\title{
$x$ Liz (VW

\section{Deformities in larval gilthead sea bream (Sparus aurata): A qualitative and quantitative analysis using geometric morphometrics}

\author{
Yves Verhaegen ${ }^{a}$, Dominique Adriaens ${ }^{a}{ }^{*}$, Tania De Wolf ${ }^{b}$, \\ Philippe Dhert ${ }^{\mathrm{c}}$ : Patrick Sorgeloos ${ }^{\mathrm{d}}$ \\ avelutionary Morphology of Vertehrates, Ghent Linwersit! K.L. Ledeganckstrat 35. B-9000 Gent, Belgum

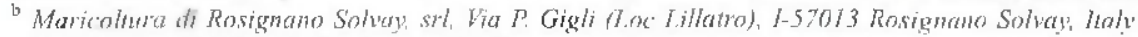

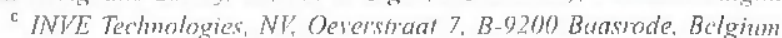 \\ ${ }^{d}$ Laboratory of Aquaculuwe and Artemia Reference Center; Ghent University, Rozier 44. B-9000 Gent, Betgrum
}

\begin{abstract}
Deformitics in commercially raised fish are a common source of downgrading of product value. During the intensive rearing of gilthead sea bream (Sparts atrakt), opcrcular deformities are the most commonly observed type of deformation (affecting up to $80 \%$ of the fisheries stock), sometjmes showing a scvere inwarl folding of the operculum. They are non-lethal malformations that appear during the larval stage but affect growth rate and morphoiogy. with a significant economic loss as a consequence. In order to exploratory quantify and qualify these deformities. geometric morphometric analyses were petformed on the extermal morphology from larvae with an age ranging from 50 to 69 days post-hatching (DPH), and on the cranial skeleton of 13 () DPH oid juveniles. The results showed scveral osteological cranial shifts and a striking left right independency associated with deoperculation. Even though a significant size difference was obscrved at 65 DPH between normal and deoperculated specimens, allometries during the examined growth stages still appear to he very similar in nomal and deoperculated specimens. At $69 \mathrm{DPH}$ fleoperculated specimens differed significantly from the normal specimens in their external morphology based on its shape variables, but the results suggest that discrimination is possible from earlier stages. Futher analyses are needed. hut the usefulness of this approach towards developing an early detection tool could he demonstrated.

(c. 2007 Elsevier B.V. All rights reserved.
\end{abstract}

Ken'urds: Sparus aurata; Opercular complex: Abnormality; Geonetric morphometrics; Ontogeny

\section{Introduction}

Gilthead sea bream (Spams aurata), being one of the first intensively cultivated species in the Mediterranean (Fishery Information. Data and Statistics Unit, Food and Agriculture Organization of the Inited Nations (FAO), 2005), has become an important research topic over the

\footnotetext{
* Corresponding author. Tel.: +32926452 19: fax: 13292645344 F.-mal address: dominicue ndrinensta ugent.he (D. Adriaens).
}

years (Koumoundouros et al., 1997a). The focus has mainly becn on aquacultural aspects, and the implementation of techniques to improve reproductive success, survival and growth (Tandler and Helps, 1985; Polo el al., 1991: Mourente et al., 1993; Parra and Yufera, 2000; Papandroulakis et al., 2002; Sadek ct al., 2004). As a maximal yield in growth and reproductive success may come into reach, problems arise with respect to the overall quality (especially deformations) of the fry and subsequent juvenile fish. Although some studies on larval quality have been performed in the past (e.g. Papema, 
1978; Koumoundouros e1 al., 1995; Furuita ct al., 2000; Boglione et al., 2001; Calu et al., 2003), future research cfforts may need to concentrate even more on a qualitative rather than quantitative improvement of the produced fish, especially in order to expose the nature behind developmental and growth problems frequently experienced in cultivating facilities. Some examples of common abnormalities in cultivated fish are axial deformities, whether or not related to swimbladder abnormalities (such as saddle-back syndrome and axial lordosis) (e.g. Alfonso et al., 2000, Boglione et al., 2001), abnormal caudal fin development (e.g. Koumoundouros et al., 1997b) and opercular deformations. Especially the distorted development of the operculum in $S$. aurata, as well as in some other cultivated species, have been a source of product downgrading and substantial economic losses over many ycars (affecling up to $80 \%$ of farmed gilthead sea bream) (Paperna, 1978; Francescon et al., 1988; Chatain, 1994: Andrades el al., 1996).

In order to improve cost-efficiency for farmed market-sized gilthead sea bream, a fast and early recognition of developing abnormalities is of utmost importance for fish farmers, as wel] as to unravel the effect of rearing parameters in order to minimize the prevalence of these deformities a priori. As a result, research efforts have been focusing on biometric screening of larvae for such deformities (Koumoundouros et al. 1997a). However, studying the pattern bchind deformities and related growth disturbances is frequently based on biometric analysis, relying on pointto-point measurements of several structures and parts of the body plan (Koumoundouros et al., 1997a; Lindesjöo et al., 1994). Such an approach is useful for studying size changes, thus growth, but is insufficient in describing aspects of shape adequately (especially size-independent shape, even when using ratios) (see Richtsmeicr et al., 2002; Dodson, 1978), thus possibly problematic when studying deformities. For that reason, geometric morphometrics allow a more complete description of shape and thus a more robust and detailed analysis of shape variation in growing and transforming fishes (Rohlf and Marcus, 1993; Adlams et al., 2004). This approach has proven to be useful for studying shape changes of commercially important fishes in the past (e.g. Cavalcanti ef al., 1999; Koumoundouros et al., 2005; Loy ct al., 1998; 2000; 2001; Valentin et al., 2002), including S. aurata (l.oy et al., 1999). All these shape analyses focused on populations in the wild, or the effect of rearing conditions on the overall body shape in adult specimens.

We performed a landmark-based geometric morphometric analysis on both external and internal (skeletal) morphology of different age groups of $S$. aurata. The specific goals of this exploratory study are: (1) to analyze quantitatively and qualitatively the nature of osteological aberrations in the skull associated with deoperculation in 110 day old juveniles, and (2) to verify to what degree shape changes in the external morphology (total body shape) co-occur with opercular deformities between 50 and 69 days post-hatching. Such an approach will assist in future efforts to allow a fast recognition protocol for delecting early opercular deformation in cultivated gitthead sea brean.

\section{Material and methods}

\subsection{Rearing conditions}

All specimens originate from the commercial sea bream hatchery Maricoltura di Rosignano Solvay (Italy). Eggs were obtained from a mixed broodstock of reared and locally wild caught adults. The broodstock was fed a mixed diet of Lansy Breed ${ }^{k \prime}$ (INVE Aquaculture NV, Belgium) pellets and fresh seafood (shrimps, mussels, crabs and fish). Spawning occurred under regulated light and temperature conditions in $2800 \mathrm{l}$ tanks. The collected eggs hatched in a 1401 incubation tank approximately $48 \mathrm{~h}$ after spawning and were transferred indoors to $6000 \mathrm{l}$ larval rearing tanks after $24 \mathrm{~h}$. Initial rearing density was approximately 150 larvae/l. Larvae were raised under a scmi-closed circuit of filtered natural scawater $(39 \%$ salinity) originating from the nearby coast. Temperatures and dissolved oxygen concentrations were continuously kep1 closely to $19{ }^{\circ} \mathrm{C}$ and between 6-12 ppm, respectively. The following light intensity regime were applied: 0-1 DPH at $80 \mathrm{~lx} .2-3 \mathrm{DPH}$ at $250,4-13 \mathrm{DPH}$ at 400 , 14-39 DPH at $250 \mathrm{~lx}$ and subsequent weaning at natural shaded sunlight $(4000 \mathrm{~lx})$. High aeration during $0-1 \mathrm{DPH}$ kept passively moving Jarvae suspended, with aeration at low level during green water phase (sufficient to distribute algae over water column). After this phase passive aeration induced by water flow was sufficient. The creation of water currents was minimized through the vertical position of the water inlet just above the water surface to allow a natural swimming behaviour of the developing fish. As from $48 \mathrm{DPH}$, the post-metamorphic phenomenon of schooling was prevented by placing a vertically submerged net in the circular tanks.

Surface skimmers were used to inhibit lipid film formation on the water surface (Chatain and OunaisGuschemann, 1990). The 'green water' technique was applied during the period 3-28 DPH, using two phytoplankton strains (Nannochloropsis sp. and Isochrysis $s p$.). The larvae were fed live feed starting on day three 
(successively with Brachionus $s p$. Biotype Cayman, INVE Artemia AF strain and INVE Artemia EG strain) followed by INVE Proton 1, Proton $2 / 3$ and Proton $2 / 4$ artificial diets. After $48 \mathrm{DPH}$ the batch was separated in two fractions, using a grader with $1.5 \mathrm{~mm}$ mesh-size, and then transferred scparately to 10,000 i weaning tanks.

\subsection{Samples}

For the osteological analysis, eleven normal and ten deoperculated specimens were sampled from a batch of 110 DPH old juveniles on the 1 I th of March 2004. We will apply the tenn "deoperculation" for any kind of defommation where the opercuinm shows microscopically visible signs of opercular reduction or shape distortions. For the external morphology, a total of 433 specimens were sampled at seven time intervals $(41,45,50,55,61,65$ and $69 \mathrm{DPH}$ ) during the period December 6th 2004 till January 3 rd 2005, each sample consisting of 31--120 specimens and representing a fotal standard length $\left(L_{\mathrm{S}}\right)$ range of 7.2 $22.0 \mathrm{~mm}$. Furthermore, five wild caught larvae (17.3$18.0 \mathrm{~mm} L_{\mathrm{S}}$ ) were obtained from a local fisherman.

All sampled specimens were anaesthetized using an overdose of MS-222. ( $100 \mathrm{ppm}$ ) and were fixed and stocked separately in a $4 \% \mathrm{NaH}_{2} \mathrm{PO}_{4}-\mathrm{Na}_{2} \mathrm{HPO}_{4}$ buffered formalin.

A whole-mount clearing and staining of the 21 juveniles, sampled for the osteolngical analysis of the skull and pectoral girdle, was carried out using the methods of Hanken and Wasscrsug (1981) and Taylor and Van Dyke (1985). Both lateral views of all specimens were photographed using a Colorview 8 digital camera mounted on an Olympus SXZ-9 sterenscopic microscope, with analysis Docu 3.00 (Soft Imaging System GmbH) software. Before being photographed, specimens were positioned as perfectly lateral as possible using the overlap of paired anatomical structures as an important guidance, in order to minimize possible slrape variation duc to suboptimal positioning. 50 of the 433 specimens for the extemal morphology analysis couldn't be positioned adequately because of an abnormal flexion of the body (natural and/or through fixation), and were thus omitted from further analysis. As no reliable markers for the body midline could be discerned on the early larval stages, the unbending module in tpsUtil was not performed (Rohlf, 2004a). All photographs of the right hody sides where then minored in order to allow the comparison of left and right sides in a single analysis. Standard lengths $\left(L_{S}\right)$ were measured on the digital images using analysis Docu 3.00 (Soft Imaging System GmbH) softwarc. The nomenclature used to describe the skeletal structures is based on Faustino and Power (2000)

\subsection{Landmark data}

Landmark data were gathered using tpsUtil (Rohlf, 2004a) to construct the tps-files and tpsDig for digitising landmark positions on the digital images (Rohlf. 2004b) (freeware at http://life.sunysb.edu/morph). For the two datasets, a set of homolngous landmarks was digitised in two dimensions. Land marks chosen were so-called type 1 and type 2 landmarks, thus allowing a reliable representation of the actual shape variation (instead of measuring error noise) (for a definitinn of these two types, see Bookstein, 1990). An estimation of digitising and orientation elror, however, was performed (see below). The osteology dataset included a total of 21 homologous landmarks that were digitised bilaterally on the 21 specimens, thus yielding 42 landmark configurations to be analysed (Fig. I). Landmarks were chosen in order to have a good representation of the overall skull shape with respect to the vertebral column, but especially with a detailed representation of the opercular region. Following landmarks were used: (1) the anterovential tip of the premaxillary bone (typc 2), (2) the caudal tip of the premaxillary bone (type 2), (3) the anterior tip of the dentary bone (type 2), (4) the mediodorsal suture between rasal and frontal bone (type 1), (5) the dorsal point of contact betwcen infraorbital bones thrce and four (type 1), (6) the anterodorsal lip of the sphenotic (type 1), (7) the postcrodorsal tip of the supraoccipital bone (type 2), (8) the posterior tip of the post-temporal bone (type 2), (9) the postcrodorsal tip of the preopercular bone (type 2), (10) the posterodorsal lip of the opercular bone (type 2), (11) the caudal tip of the opercular bone (type 2), (12) the ventral tip of the opercular bone (type 2), (13) the posterior tip of the subopercular bone (type 2), (14) the ventral end of the contact zone between subopercular and interopercular bone (type I), (15) the anterior tip of the interopercular bone (type 2), (16) the overlap of the subopercular--interopercular bone suture with the posterior margin of the preopercular bone (type 1), (17) the anterior tip of the preopercular bone (type 2), (18) the ventral tip of the cleilhnum (type 2), (19) the caudal tip of the clcithrum (typc 2), (20) the anterior tip of the neural arch of the third vertebra (type 2), (21) the anterior tip of the neural arch of the fifth vertebra (type 2).

The external morphology dataset shape model relied on a total of 16 landmarks (Fig, 2). Specimens smaller than $11.4 \mathrm{~mm} L_{\mathrm{S}}$ (all specimens younger than $50 \mathrm{DPH}$ and three spccimens aged $50 \mathrm{DPH}$ ) were further omilted from the geometric morphometric analysis because of a lack of landmarks that could he homologised on these specimens. Of the 310 specimens left and right sides were digitised and analysed 
separately (as most landmarks in both views were identical as they were positioned in the medial plane), yielding two datasets (left and right). Again, landmarks were of type 1 and 2, with the exception of one (landmark 15). Landmarks were chosen to represent the overall body shape. as well as the position of the pectoral fin, the back of the skull and the eyc. As specimens were categorised as normal or deoperculated based on visible abnormalities in the opercular region, the shape model of the extcrnal morphology did not include landmarks in the opercular region, thus allowing an independent analysis of shape changes cooccurring with deoperculation. Following landmarks were used: (1) the anterodorsal (ip of the premaxillary (type 1), (2) the posterior border of the skull (type 1), (3) the base of the first spine of the dorsal fin (type 2). (4) the base of the first soft ray of the dorsal fin (type 2), (5) the base of the last soft ray of the dorsal fin (type 2), (6) the dorsal onset of the caudal fin (type 1), (7) the midlateral posterior edge of the peduncle (type 2), (8) the ventral onset of the caudal fin (type 1), (9) the base of the last ray of the anal fin (type 2), (10) the base of the first ray of the anal fin (type 2), (11) the base of the pelvic fin (type 1), (12) the posteroventral tip of the mandibular (type 1), (13) the base of the last (upper) l'ay of the pectoral fin (type 2), (14) the base of the first (lower) ray of the pectoral fin (type 2), (15) the centre of the eye (type 3), (16) the posterior tip of the skull (type 1).

\subsection{Morphometrics}

In order to remove all variation in size, rotation and position (with respect to the image frame), a standardisation was done for all three parameters. For that, a Generalised Procrustes Analysis (GPA) was performed where all landmark configurations were scaled to the same centroid size $(C S=1)$, aligned with centroids being superimposed and rotated until a maximal fit of homologous landmarks (Rohlf and Slice, 1990). This yields a dataset reflecting only differences in true shape. Shape differences were calculated between all specimens, as well as between all specimens and a consensus ( $i$ e. an average landmark configuration of all specimens in the dataset). The fitness of the dataset for further statistical analysis was tested using tpsSmall (Rohli. 2003), so that the distribution of shape distances in the non-Euclidean Kendall shape space (i.e. Procrustes distances) between specimens is properly represented in the Euclidean tangent space (i.e. tangent distances) (for a discussion on these shape spaces, see Rohlf, 1996). All datasets proved to be fit for analysis (correlation between Procrustes distances and tangent distances was 1.0000).

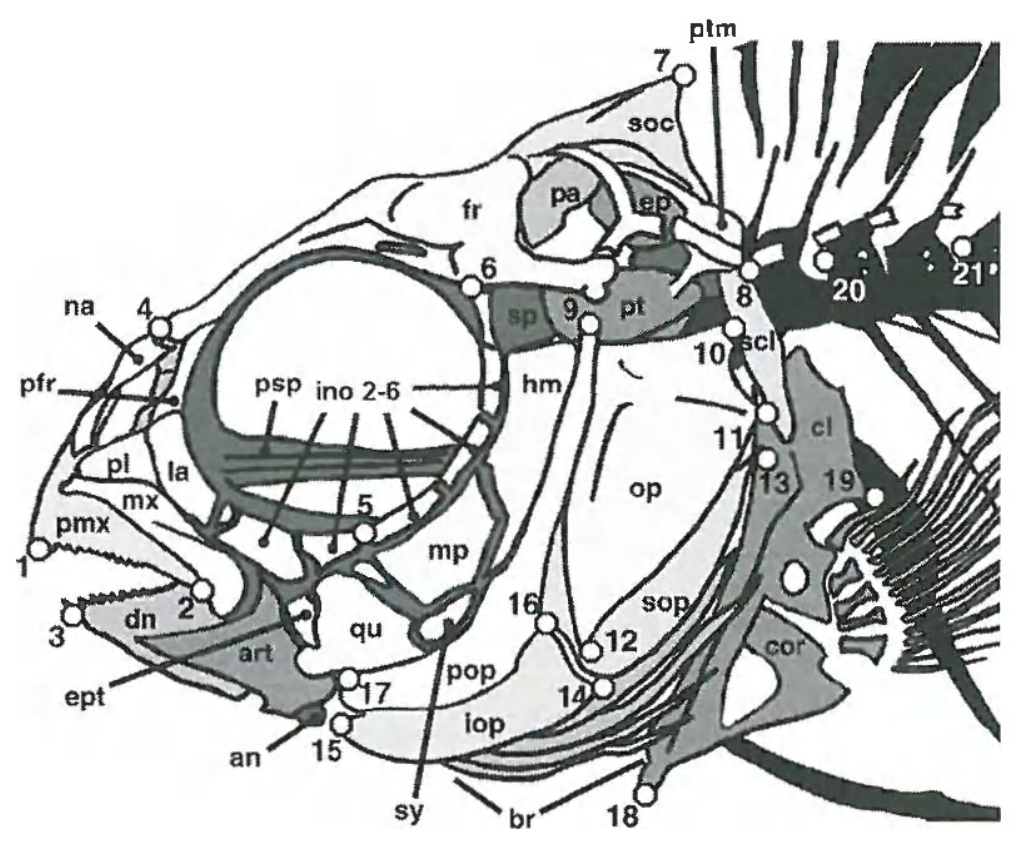

Fig. I. Drawing of the cranial osteology and the landmarks applied. an, angular; art, articular; br, hranchiostegal rays; cl, cleithrum; cor, coracoid; dn, dentary; ept, ectopterygoid; ep, epiotic; fr, frontal; him, hyomandibular; ino 2-6, infrarbital two ro six; iop, interopercular; la, lacrimal; inp, metapterygoid; mx, maxilla; na, nasal; op, opercular; pa, parielal; pfr, prefrontal; pl. palatine: pmx, premaxilla: pop, preopercular; psp, paraspleneid; pt, pterotic; ptm, pusttemporai; qu, quadrate; scl, supraclcithrum; soc, supraoccipital; sop, suhopercular; sp. sphenotic; sy. symplectic. 


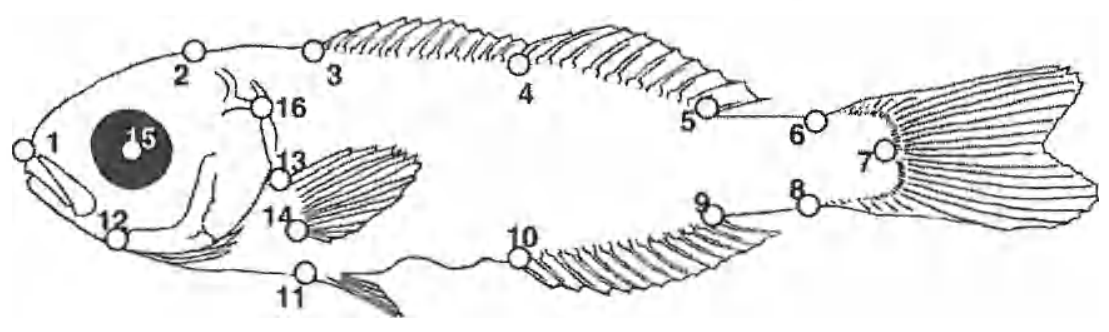

Fig. 2. Drawing of the external morphology of a large $50 \mathrm{DPH}$ old specimen $\left(13.9 \mathrm{~mm} I_{\mathrm{S}}\right)$ and the landmarks applied

\subsection{Error analysis}

Since both larval and juvenile specimens were laterally flattened, mcasuring eiror as a result of a reduction in dimensions was minimal (for a discussion on measuring errors in geometric morphometrics, see Amqvist and Mârtensson, 1998). A separate error analysis was done to estimate the amount of error induced by the action of
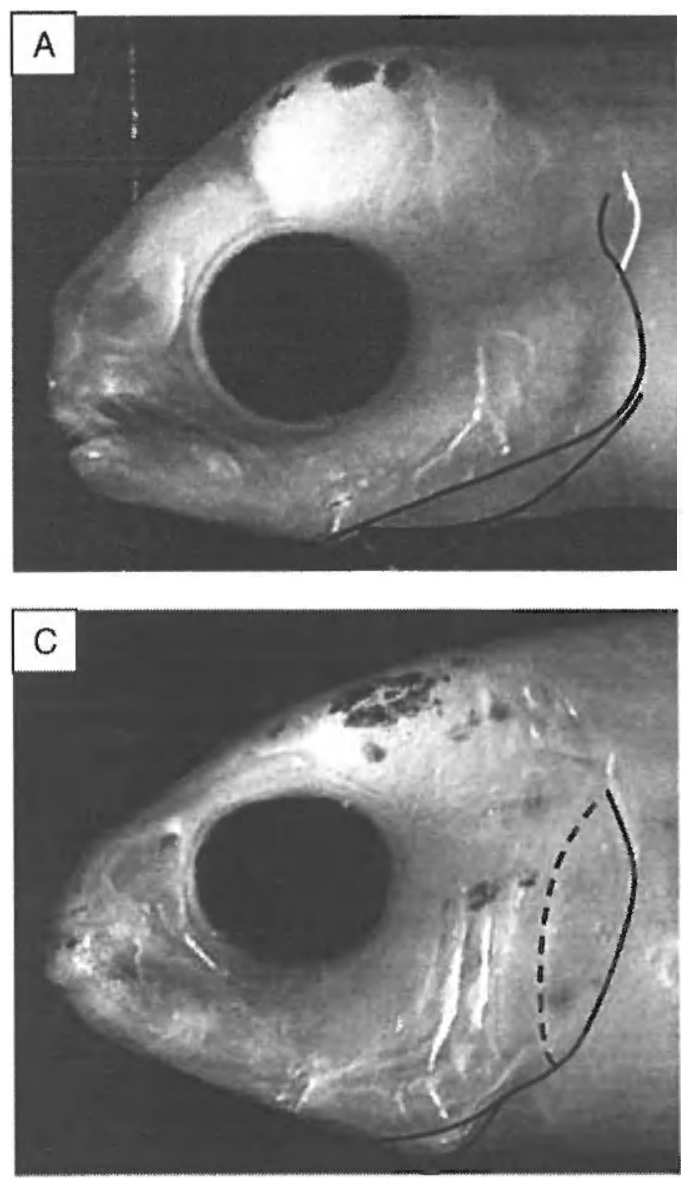

digitising, as well as that as a result of variation in positioning the specimens for imaging. An estimate of digitising enor was done by digitising ten times the same image from a single specimen of the osteological data (all specimens had a comparable size) and from two specimens (the largest and smallest) from the external morphology data. The estimate of artificial shape variation as a result of variation in the positioning of the specimens was done by
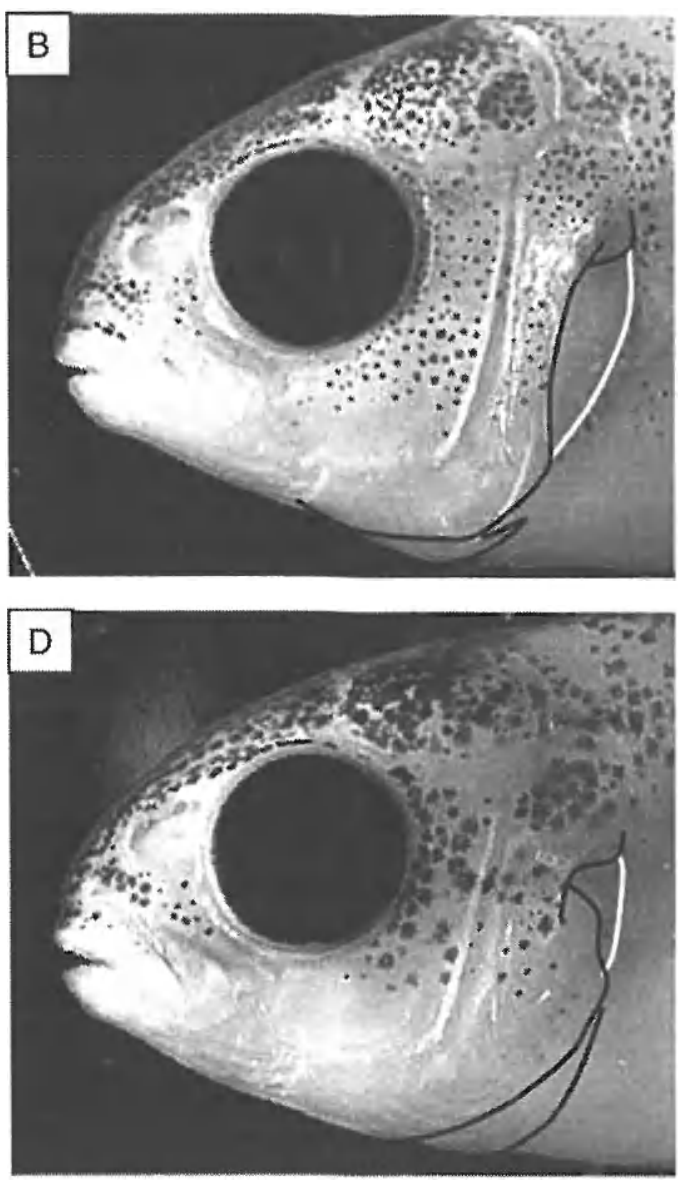

Fig. 3. Fxternal morpholog:' of the head region, showing the onset of deoperculation. A. Early opercular deformation in a 40 DIII, $8.5 \mathrm{~mm} L_{S}$ post-larva: B. severe stage of opercular cleformation in a $69 \mathrm{DPH}, 19.5 \mathrm{~mm} L_{\mathrm{S}}$ juvenile; C. aberrant type of opercular deformity in a $55 \mathrm{DPH}, 14.7 \mathrm{~mm} L_{\mathrm{S}}$ juvenile; D. abeirant type of opercular cleformity in a $69 \mathrm{DPH}$ I $8.4 \mathrm{~mm} L_{\mathrm{S}}$ juvenile. Black lines indicate the caudal edge of the operculum and branchiostegal rays, white lines mark the caudal edge of the gill cavity. The crest of an abnonnally fight folding is indicated hy a dashed black linc in Fig. $3 C$. 


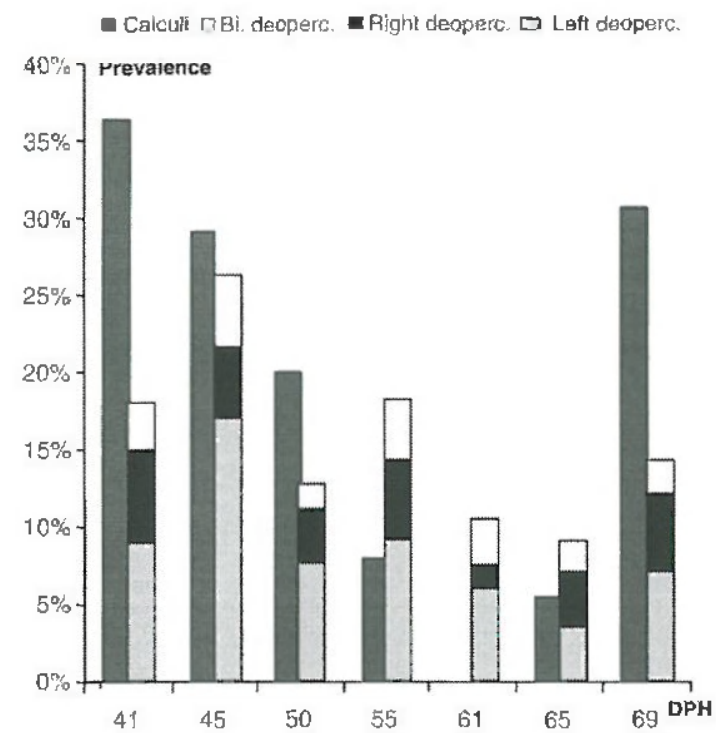

Fig. 4. Prevalence of urimary calculi and opercular deformities, for al] studicd age classes.

using these three specimens, but which were now positioned and photographed ten times repeatedly.

The average Prociustes distances of these datasets were then expressed as percentage of these distances of the total dataset, revealing an estimate of the amount of shape variation which can be attribuied to digitising and positioning errors.

\subsection{Statistical analyses}

Variables describing shape variation (i.e. partial warps) in the datasets, based on the $2 \mathrm{D}$-coordinates, were calculated using tpsRelw (Rohil, 2005). For the

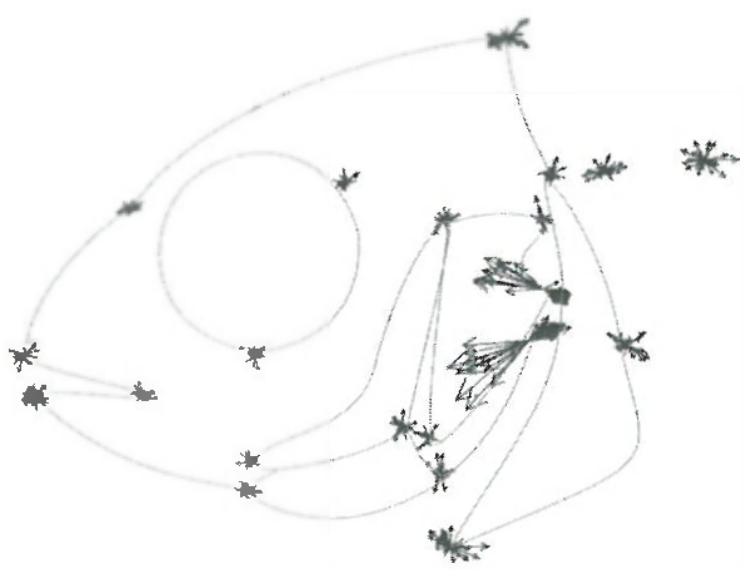

Fig. 5. Consensus configuration of the ostcological datasct, with differences in landmark position of aliencd specimens indicaled as vectors. statistical analysis, both uniform and non-uniform partial warps were included. The obtained matrices of partial warp scores of all specimens (weight matrix) in both datasets were subsequently submitted to a Principal Component Analysis (also called a Relative Warp analysis when using partial warp scores) (Rohlf, 1993). By doing so, the total shape variation was decomposed into a new set of variables (i.e. relative warps) that describe the most important variation in the datasets. This was also done using tpsRelw, which was also used to generate deformation grids to visualise the explained shape variation (with respect to the consensus configuration). Scaling was set cqual $(\alpha=0)$ for local and diffuse non-uniform shape changes (Rohlf, 1993; Rollf ct al.. 1996).

For the extemal morphology dataset, a discriminant function analysis (DFA) was performed on the shape variables (using the weight matrix) to test the significance of existing differences between normal and deoperculated specimens for the different length and age classes (Statistica 6, Statsoft Inc.). As mentioned, a priori discrimination between normal and deoperculated specimens was performed by a microscopical analysis of the opercula. Both canonical scores, as well as relevant statistical parameters (Squared Mahalanobis distance, $F$-valuc and $p$-levels) were calculated using Statistica 6.0 (Statsoft, Inc.). For all statistical analyses, $p$-levels smaller than 0.05 were considered as significant. The shape changes associated with the canonical variates were visualised using tpsRegr (Rohlf, 2004c), including a randomisation test (with 1000 permutations).

As centroid size correlated highly with the measured standard lengths $\left(R^{2}>0.98\right.$, $)$ we preferred the latter as size parameter, because it can be more easily obtained during the daily monitoring of stocks in fish farms

Table 1

Pcrcent of variation explained by the first ten relative warps of the nsteological and both extemal morphology datasets

\begin{tabular}{lccc}
\hline RW & \multicolumn{2}{c}{ \%of variation explained } \\
\cline { 2 - 4 } & Osteology & Left cxternal & Right external \\
\hline 1 & $68.23 \%$ & $51.52 \%$ & $54.00 \%$ \\
2 & $6.66 \%$ & $10.42 \%$ & $9.42 \%$ \\
3 & $5.56 \%$ & $7.79 \%$ & $7.02 \%$ \\
4 & $3.46 \%$ & $4.45 \%$ & $4.42 \%$ \\
5 & $2.63 \%$ & $3.67 \%$ & $3.25 \%$ \\
6 & $2.06 \%$ & $3.29 \%$ & $2.98 \%$ \\
7 & $1.70 \%$ & $2.74 \%$ & $2.53 \%$ \\
8 & $1.54 \%$ & $2.23 \%$ & $2.22 \%$ \\
9 & $1.39 \%$ & $1.76 \%$ & $1.90 \%$ \\
10 & $0.95 \%$ & $1.69 \%$ & $1.55 \%$ \\
\hline
\end{tabular}




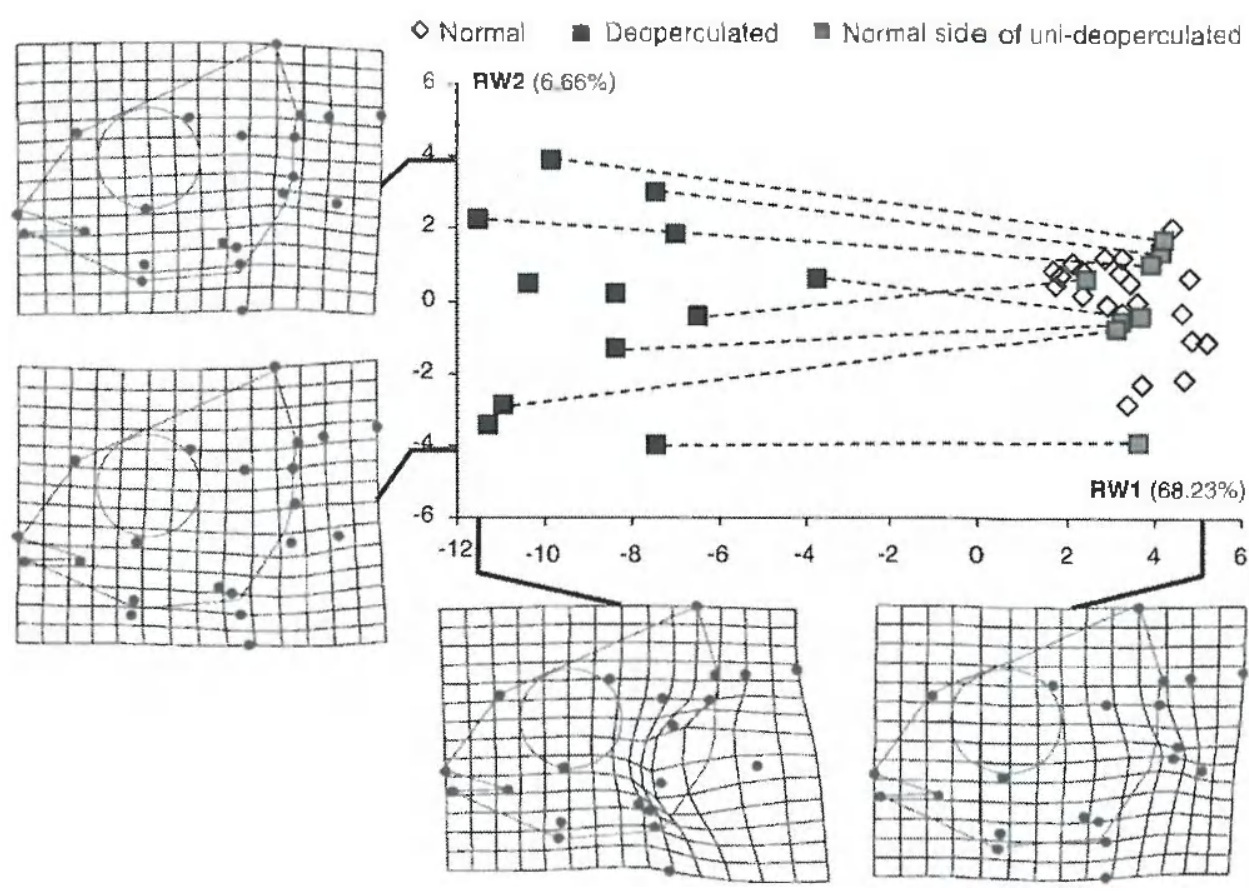

Fig. 6. Scatter plot of relative warp I versus relative warp 2 scores. showing a separate ciustering of the normal (diamonds) and abnormal specimens (filled squares). The normal sides of the skull of unideoperculated fishes clearly fall into the normal cluster (empty squares). Dotted lines interconnect nommal and abnormal sides of unilaterally deoperculated specimens. Shape variation explained thy the relative warps is visualised by the deformation grids (showing the shape differences with respect to the consensus).

\subsection{Calculation of inflection points}

In order to objectively calculate the most significant shifts in shape changes (expressed as relative warp 1) versus size $\left(\log L_{\mathrm{S}}\right)$, inflection points werc calculated as proposed by Van Snik et al. (1997): the data was logtransformed, regression lines were calculated for $x_{\text {min }}$ until $x_{\text {intermediate, }}$ and for $x_{\text {intermediate }}$ to $x_{\text {niax }}$, where $x_{\text {intermediate }}$ was a variable iteratively ranging from $x_{\text {min }}+2$ to $x_{\max -2}$. T-tests were done to check whether the group

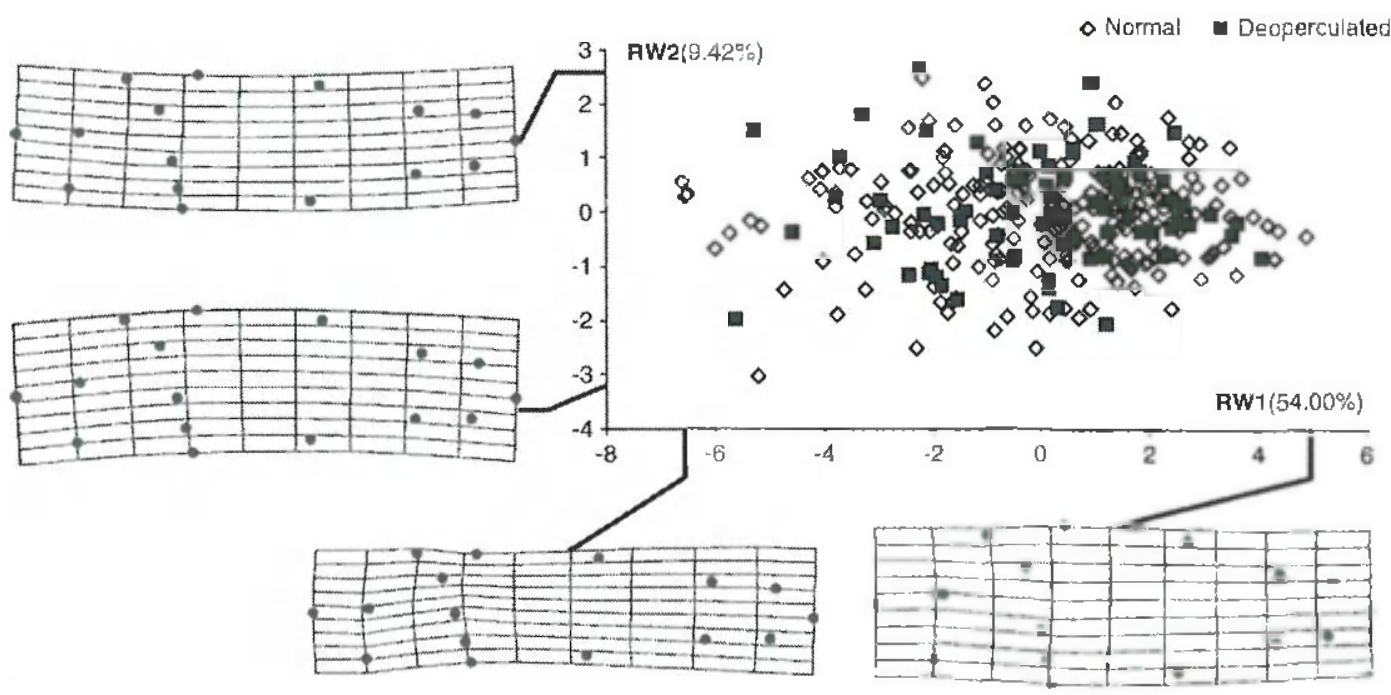

Fig. 7. Scatter plot of relative warp I versus relative warp 2 scores of the analysis of the right body side, showing the overlap of the nornal (dianonds) and abnormal specimens (scyuares). Shape sariation explained by the relative warps is visualised hy the deformation grids \{showing shape difference witl: respect to consensus, minrored). 


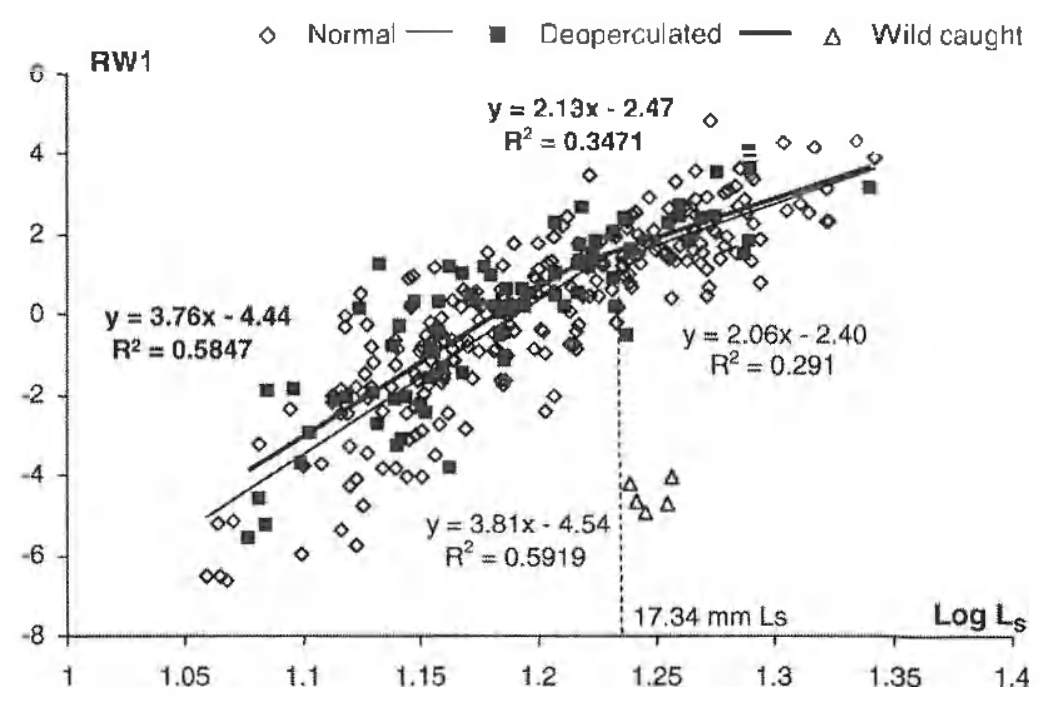

Fig. 8. Scatterplot of RWI versus borly size (log-transformed $I_{\mathrm{S}}$ ) of the analysis of the right body side, with the indication of the calculated inflection point.

of growth coefficicients for $x_{\text {min }}$ to $x_{\text {intermediate }}$ significantly differs from the group of growth coefficients for $x_{\text {intermediale }}$ to $x_{\max }$. The $x_{\text {intermerliate }}$ value that shows the largest significant $t$-stat is defined as the inflection point.

\section{Results}

\subsection{Size and deoperculation}

Opcrcular deformities were already visually detectable in the smallest and youngest specimens $(8.0 \mathrm{~mm}$ $L_{\mathrm{S}}, 40 \mathrm{DPH}$ ) as a small notch dorsally in the free opercular edge (Fig. 3A shows an $8.5 \mathrm{~mm} L_{\mathrm{S}}$, $40 \mathrm{DPH}$ specimen). During this phase the operculum is still largely unossified and a large posteroventral part is resting against the pectoral girdle. As the post-Jarvac grow the deformity expands ventrally and ultimately also affects the branchiostegal rays, with a bending of the operculum into the gill cavity as a result. Only four aberrant opercular abnormalities were detected afier metanorphosis: a single specimen showed unilaterai inwardly folded branchiostegal rays while the operculum did not show the expected associated deformity (Fig. 3C). The operculum, howcver, showed an abnormal dorsoventral ridge, which probably is a consequence of a previous inward folding. In three post-metamorphic specimens only the dorsocaudal tips of the opercula were severely folded inward and deformed (Fig. 3D).

The mortality rate during the studied rearing period was negligible $(0.03 \%$ ). The prevalence of opercular deformities seems to decrease during metamorphosis (11.0-22.0 TL (Total length), as mentioned by Koumoundouros et al., 1997a) and to increase again afterwards (Fig. 4). The presence of urinasy calculi in the gall bladder, which is a typical symptom of stress, showed the same pattern (although not directly correlated. with opercular deformities, $R^{2}=0.067$ ) (Fig. 4). Of the 38.3 specimens screencd $28.5 \%$ showed an opercular deformity, of which $18.3 \%$ bilateral. In both datasets there were more Icft than right dcoperculations (ostcological

Table 2

Statistics of the discriminant function analyses of the five age classes

\begin{tabular}{|c|c|c|c|c|c|c|c|c|c|c|}
\hline \multirow[t]{2}{*}{ Analysis group } & \multicolumn{5}{|c|}{ Left } & \multicolumn{5}{|c|}{ Right } \\
\hline & $50 \mathrm{DPH}$ & $55 \mathrm{DPH}$ & 60 DPII & $65 \mathrm{DPH}$ & 69 DPH & 50 DPH & $55 \mathrm{DPll}$ & $60 \mathrm{DPH}$ & $65 \mathrm{DPH}$ & $69 \mathrm{DPH}$ \\
\hline Wilks' lambela & 0.510 & 0.123 & 0.428 & 0.660 & 0.658 & 0.577 & 0.073 & 0.124 & 0.711 & 0.513 \\
\hline$\chi^{2}$ & 26.270 & 39.797 & 14.437 & 34,099 & 30.520 & 21.418 & 49.606 & 35.525 & 28.009 & 48.777 \\
\hline$d f$ & 28 & 28 & 28 & 28 & 28 & 28 & 28 & 28 & 28 & 28 \\
\hline$p$-level & 0.558 & 0.069 & 0.984 & 0.198 & 0.339 & 0.808 & 0.007 & 0.155 & 0.464 & 0.009 \\
\hline Majalanobis $D^{2}$ & 4.846 & 31.610 & 8.005 & 3.439 & 2.570 & 3.690 & 55.972 & 42.377 & 2.716 & 4.706 \\
\hline$F$-value & 0.875 & 1.505 & 0.178 & 1.235 & 1.100 & 0.606 & 2.665 & 0.945 & 0.975 & 2.015 \\
\hline$d f$ & 28,26 & 28,6 & 28,4 & 28,69 & 28.60 & 28,26 & 28.6 & 28,4 & 28,69 & 28.60 \\
\hline$p$-level & 0.637 & 0.37 .1 & 0.998 & 0.237 & 0.369 & 0.853 & 0.111 & 0.605 & 0.514 & 0.012 \\
\hline
\end{tabular}


dataset: $n=21$, of which $33.3 \%$ left and $23.8 \%$ right deoperculated, external morphology datasct: $n=383$, of which $20.2 \%$ left and $13.6 \%$ right deoperculated); but only in the extental morphology dataset this difference was significant (Fisher's exact test two-tailed $p$-value $=0.046$ ). Only in the largest age class (65 DPH) a small significant difference in average length could be observed between normal and deoperculated specimens. $\left(L_{\mathrm{S} \text { normal }}=17.2 \pm\right.$ $1.8 \mathrm{~mm}, I_{\mathrm{S}}$ deopste. $=16.4 \pm 1.1 \mathrm{~mm}, F_{(79,17)}=2.944$, $p=0.0074, T_{(43)}=2.58, p=0.013$ ). Contradictoly to these results, the deoperculated specimens in the osteology dataset (juveniles of $110 \mathrm{DPH}$ ) were bigger (normal $24.7 \pm 1.1 \mathrm{~mm} L_{S}$; deoperculated $25.3 \pm 0.9 \mathrm{~mm}$ $\left.L_{\mathrm{S}}\right)$, but this difference was not significant $\left(T_{\{19\}}=\right.$ $-0.78738, p=0.220386$ ).

\subsection{Skeletal shape and deoperculation}

The analysis of the osteological dataset yielded two uniform and 36 non-uniform partial warps that were included in the analyses. The consensus configuration, with aligned specimens superimposed (thus showing
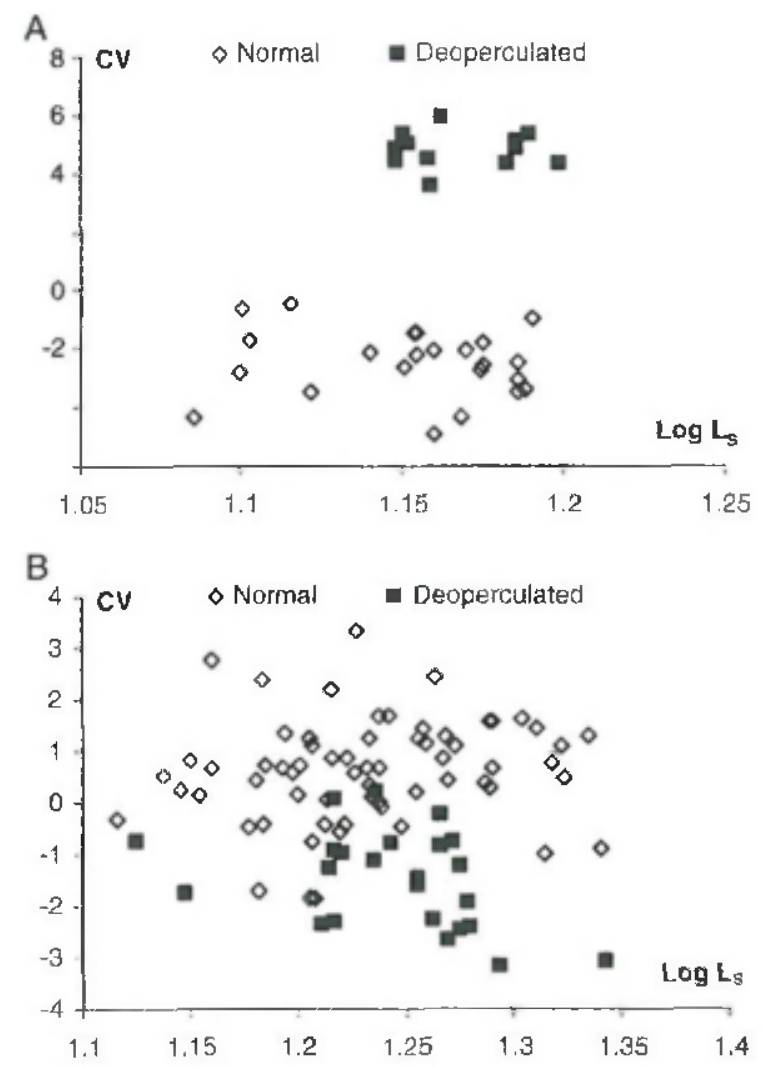

Fig. 9. Scatterplots of the significant canonical variates versus the logarithm of the Standard length (right body side): A. $55 \mathrm{DPI}$; B. 69 DPII.

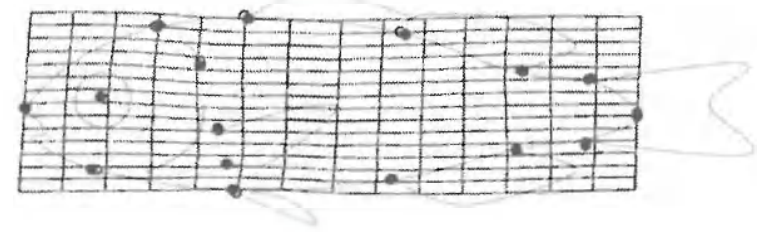

Fig. 10. Deformation grid visualised through TPSRegr, representing the shape difference between a low $(-3,17)$ and high $(3,35) \mathrm{CV}$-score of the $69 \mathrm{DPH}$ semple. The regression of the shape variables on the $\mathrm{CV}$-scores was subjected to a permutation test (percent unexplained $97.90 \%, 0.10 \%$ Lambda values $-0.00000003,9.90 \%$ Goodall $F_{\text {-values }}-1.864$ ).

variation in landmark positions) showed a differential variation in landmark position, with the largest variation in the two landmarks at the posterior border of the opercular bone (Fig. 5). An average of $6.78 \%$ of the total variation in the dataset could be attributed to both digitisation and orientation error. The largest digitisation and orientation crror were situated at landmark 12 (11.82\% of total digitisation error) and landmark 18 (12.33\% of total orientation error) respectively. The percentages of variation explained by the relative warps ( 38 in total) are given in Tablc 1. The first relative warp, which explained $68.23 \%$ of the total shape variation in the dataset, clearly separated the deoperculated and normal configurations, while the other relative warps did not (Fig. 6). Relative warp 1 thus largely represents the shape changes in the head region associated with deoperculation. Besides the expected forward shift of the candal margin of the opercular and suhopercular bone (as observed externaliy), other more subtle shape differences can be observed. These include an upward shift of the interopercle, angular, quadiate, the infraorbitals and the preopercular. The preorbital region, thus the snout, also shortens with respect to the other landmarks. Most striking of this analysis, however, is the obscrvation that in unilaterally deoperculated specimens, the normal sides show a shape that corresponds perfectly with bilaterally normal specimens, whereas the deoperculated sides showed all the typical shifts in the landmark configuration as in bilaterally deoperculated specimens. Apparently, the prevalence of the deformation associated with deoperculation is completely decoupled bilaterally, thus allowing an astonishing right-left asymmetry.

\subsection{Body shape and deoperculation}

The shape dccomposition of the external morphology data set generated two uniform and 26 non-uniform partial warps. The conscnsus configuration, with aligned specimens, showed that shape difference is spread all over the body but is situated mainly in the anterior part (head and abdomen). In this analysis, an average of 
Table 3

Sta1istics of the discriminant function analyses of the subsets derived from the total left and right extemal morphology datasets based on the inflection points

\begin{tabular}{|c|c|c|c|c|}
\hline \multirow{2}{*}{$\begin{array}{l}\text { Analysis } \\
\text { Group }\end{array}$} & \multicolumn{2}{|c|}{ Left } & \multicolumn{2}{|c|}{ Right } \\
\hline & $18.01 \mathrm{mmn} L_{\mathrm{S}}$ & $\therefore 18,01 \mathrm{~mm} L_{\mathrm{S}}$ & $\because 17.34 \mathrm{~mm} L_{\mathrm{S}}$ & $=17.34 \mathrm{~mm} L_{\mathrm{S}}$ \\
\hline Wilks' lambda & 0.510 & 0.123 & 0.428 & 0.073 \\
\hline$x^{2}$ & 26.270 & 39.797 & 14.437 & 49.606 \\
\hline$d f$ & 28 & 28 & 28 & 28 \\
\hline$p$-level & 0.558 & 0.069 & 0.984 & 0.007 \\
\hline Mahalanobis $D^{2}$ & 4.846 & 31.610 & 8.005 & 55.972 \\
\hline$F$-value & 0.875 & 1.505 & 0.178 & 2665 \\
\hline$d f$ & 28,215 & 28,38 & 28,199 & 28,54 \\
\hline$p$-level & 0.637 & 0.321 & 0.998 & 0.111 \\
\hline
\end{tabular}

$28.18 \%$ and $17.62 \%$ of shape variation could be attributed to digitisation error for the smallest and largest specimen respectively, whereas an average of $9.06 \%$ and $16.52 \%$ of shape variation could be attributed to orientation crrors. The largest digitisation errors are situated at landmark 6 (18.34\% of digitisation crror) in the smallest and at landmark $9(9.74 \%)$ in the largest specimen. The largest orientation errors were situated in landmark $2(21.57 \%$ of total orientation crror) and landmark $1(19.75 \%)$ of the sinallest and largest specimen respectively.

None of the relative warps ( 28 in total) explained shape variation that allowed to distinguish two or more groups. Relative warp 1 (Fig. 7) accounted for $54.00 \%$ of the total shape variation in the right side dataset $(51.52 \%$ in the analysis of the left body sides) and reflects an overall heightening of the body, most extensive in the posterior head region and abdomen, as well as a lengthening of those regions. Bccause of the higher percentage of variation explained by RW 1 for the right side data, the latter will be discussed further where the results of left and right body side analyses are identical. The largest dorsoventral expansion seems to be situated in the posterior margin of the skull and the cleithral region, expanding the nape (the dorsal region between the end of the skull and the beginning of the dorsal fin) and shifting the pectoral and pelvic fins downwards. Because of the expansion of skull and abdomen, the tail region diminishes relatively in size. Relative warp 2 (Fig. 7) explains $9.42 \%(10.42 \%$ in the left analysis) of total shape variation and is characterized by an overall dorsoventral curving of the body, probably as an artefact due to the formalin-fixation.

\subsection{Growth allonetries and deoperculation}

The regression analysis and $t$-testing for inflection points shows that scores of RWl of the external morphology analysis fit nicely onto body size (logvalues of $L_{\mathrm{S}}$ ) with an allometric shift at $17.34 \mathrm{~mm} L_{\mathrm{S}}$ (18.01 $\mathrm{mm} L_{\mathrm{S}}$ in the left dataset) (Fig. 8). No apparent differences in the relation between shape and size in normal versus deoperculated specimens could be observed (the inflection points, the intercepts and slopes of the regression lines are very similar, but the $R^{2}$-values for the normal specimens, however, were lower).

Five specimens, caught localiy at the coast near the hatchery, were included in the analysis for comparison and showed a totally different relationship between shape (RWi) and size ( $\left.\log I_{S}\right)$ (Fig. 8): the wild caught spccimens obtained the same RW1-scores (thus had a comparable shape) as reared specimens of a much smaller size $\left(17.3-18.1 \mathrm{~mm} L_{\mathrm{S}}\right.$ versus $13.3 \mathrm{~mm} L_{\mathrm{S}}$ ), possibly indicating an accelerated growth-development relationship under intensive rearing conditions.

It is only in the $69 \mathrm{DPH}$ age class that a significant difference between the normal and deoperculated cluster was observed, after a discriminant function analysis bascd on the shape variables of the right side $\left(\chi^{2}\right.$-test, $p<0.01$ ) (Table 2, Fig. 9B). Still, a clear separation or at least a strong polarization of the canonical variate scorcs of the two clusters was observed in all age classes. As cxample, in the $55 \mathrm{DPH}$ sample (Fig. 9A), the difference was clear in a plot of the scores but not significant $\left(F_{(28,6)}=4.147, p=0.0872, D^{2}=139.97\right)$.

The shifts in body shape associated with deoperculation at $69 \mathrm{DPH}$ are minor with the largest differences involving a reduced abdominal height (more specifically at the nape) and a posterior shortening of the lower jaw (Fig. 10).

Finally, we separated the total datasets $(n=310)$ of left and right external morphology in two subsets each, based on their inflection prints, but the discriminant function analyses of these subsets didn't reveal significant discriminations between normal and deoperculated specimens (Table 3 ). 


\section{Discussion}

Both datasets showed the occurrence of more left than right deoperculations (osteological dataset: $n=21$, of which $33.3 \%$ left and $23.8 \%$ right deoperculated; external morphology dataset: $n=383$, of which $20.2 \%$ left and $13.6 \%$ right deoperculated). Only for the extcrnal morphology dataset this difference was significant (Fisher's exact test two-1ailed $p$-value $=0.046$ ). Earlier studies on opercular deformities in sea bream all concluded that unilateral deformation was side-independent and thus was the result of a fluctuating asymmetry model (Koumoundouros et al., 1997a; Galentti et al., 2000; Beraldo et al., 2003). Our data on the other hand suggest a directional asymmetry model. Fluctuating asymmetry is believed to be a consequence of environmental factors that have an effect on developmental instability during the carly life stages (Adams and Niswander 1967; Barahona-Fernandes, 1982), while directional asymmetry is believed to be an inherited factor. Fxisting literature on the genetic influence are contradictory: according to Tave and Handwerker (1994) opercular deformities are noninheritable in Oreochronis niloticus, while inbreeding in Cichlasoma nigrofasciatum resulted in more opercular deformities (Winemiller and Taylor, 1982). A basic assumption of asymmetry research is that left and right side experience identical cnvironmental factors. This may not be the case under rearing conditions: intensive schooling in circular tanks for example may causc a different development of the sides of the body

The prevalence of higher left deoperculation numbers in the samples studied, remains to be confinmed by additional analysis focusing on the pattern behind the asymmetry.

The transformations co-occurring with opercular deformities are not only affecting the operculum itself. but also the surrounding cranial structures. Major shape changes related witl deoperculation seem to be concentrated in the postcroventral region of the skull. with an anterodorsally directed shift. Additionally, such a shift is observed in the postorbital region and the mandibular arch. Whether both transformations share the same causal factor (e.g. gene expression pattern), arc spatially interrelated, or even have independent causes, remains to be studied.

The most striking observations of the cranial deformations are that in unideoperculated specimens the deoperculated side shows identical transformations. with the same intensity, as both sides in bideoperculated specimens, while the normal side has an identical morphology to that of normal (bioperculated) spccimens. Consequently, it can be suggested that both in unilaterally and bilaterally deoperculated larvae, the morphogenetic pattern genera- ting the normal and/or deformed side on the contralateral faces in the skull is completely independent (at least with respect to deoperculation).

We could not fully confirm the results of Chatain (1994) and koumoundouros et al. (1997a), that opercular deformities affect larval size (or are at least related to it). A minor but significant size difference could only be observed in the 65 DPH sample, where normal specimens were slightly larger.

The most imporlant ontogenetic allometries (represented by relative warp one) of the normal and deoperculated groups shared a comparable slope and intercept, as well as they both experienced a clear inflection point at $17.1-18.0 \mathrm{~mm} L_{\mathrm{S}}$. which is situated at the end of the metamorphosis period (11.0-22.0 TT) as mentioned by Knumoundouros et a1. (1997a). Geometric morphometrics can be an important asset in defining the exact demarcations of metamorphic phases (as in several invertebrates) in organisms with a less pronounced metamoiphosis such as gilthead sea bream. Frequently, single morphological characters are used to dcmarcate the onset of a specific early life history phase, such as the formation of fin rays or the completion of the fin ray formation (see for exansple Balon, [975). Other studies do involve changes in allometric variables (e.g. Koumoundouros et ai., 1995). Whether or not S. aurata undergoes a true phase of melamorphosis can be argued about. In any casc, this study indicates the existence of marked shifts in the pattern of their ontogenetic shape changes at about $17 \mathrm{~mm} L_{\mathrm{S}}$.

Koumoundouros et al. (1997a) described a temporary stasis in the presence of opercular deformities during metaniorphosis. Our results, on the contrary, even indicate a decrease in the rate of deoperculation during metamorphosis, while mortality was negligible during the studied stages $(0.03 \%)$. Deoperculated specimens can regenerate their damaged opercula to a great extent during later development, as described by De Wolf et al. (2004). Therefore it is likely that regeneration may also occur during metamorphosis. The four aberrant opercular abnormalities, which were only encountered after metamorphosis, could be the result of an incomplete recovery. This remains to be verified, however.

Chatain (1994) microscopically observed the earliest opercular deformities at $12-15 \mathrm{~mm}$ TL. We could detect opercular deformations microscopically from 8.0 nาm $L_{\mathrm{S}}$ and $40 \mathrm{DPH}$ on, as a local shortening (or possible inward folding) of the dorsal opercular edge. However, carlier microscopical discrimination is very likely to be possible, as these specimens were the youngest and smallest stages examined. The use of bone-staining and histologica! methods allowed the identification of 
Faustino, M.. Power, D.M., 2000. Osteologic development of the viscerocranial skeleton in sea breant altemative ossification stralegies in teleost fish. J. Fish Biol. 58, 537-572.

Francescon, A., Freddi. A., Barbaro, A., Giavenni. R., 1988. Daurade Spans aurafa L. reproduite artificiellcment et daurade sauvage. Expériences paralleles en diverses conditions d'élevage. Aquaculture $72,273-285$

Funila. H., Tanaka, H., Yamamoto, T.. Shiraishi. M., Takeuclii, T., 2000. Effects of n-3 IIJFA levels in broodstock diet on the reproductive performance and egg and larval quality of the Japanese flounder. Paralichthes olinaceus. Aquaculture 187, $387-398$.

Fishery Information, Data and Statistics Unit, Food and Agriculture Organization of the United Nations (FAO), 2005. FISHSTAT Plus: Universal software for fishery statistical time series, version 2.3. (avail-

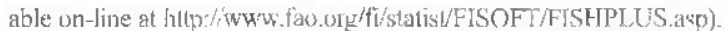

Galeotti, M.. Beraldo. P.. de Dominis, S., D Angelo. I... Aallestrazzi, R.. Musetti, R., Pizzolito, S., Pinosa. M., 2000. A preliminary histological and uiltrastructural study of opercular anomalies in gilthead sea bream (Spurzis aurata). Fish Phys. Biochem. 22, 151- 157.

Hanken, I., Wassersug, R., 1981. The visible skelcton. A new double-stain technique reveals the native of the 'hard' tissues. Funct. Photogr. 16, $22-26$.

Koumoundouros. (i., Kiriakos, Z., Divanach, P., Kentouri, M., 1995. Morphometric relationships as criteria for the craluation of larral quality of gilthead sea bream. Aquacult. Int. 3, 143-149.

Koumoundouros, G.. Oran. G.. Divanach. P. Stefanakis. S., Kentouri. M.. 1997a. The opercular complex deformity in intensive gilthead sea bream (Sparts anrata L.) larviculture. Moment of apparition and description. Aquaculture 156, 165-177.

Koumoundouros, G., Gagliardi, F., Divanach. P.. Boglione, C. Calaudelia, S., Kentouri, M., 1997b. Nurnal and abnormal osteological developnent of caudal fin in Spants aurata I.. firy. Aquaculture 149, $215-226$.

Koumoundouros, G., Kouttouki, S.. Georgakopoulou, E., Papadakis, I., Maingot, E., Kaspiris, P., Kirjakou, Y., Georgiou. G., Divanach, P., Kentouri, M., Mylonas, C.C., 2005. Ontogeny of the shi drum Unbrino cirnsa (Linnacus 1758), a candidate new spccies for aquaculture. Aquacult. Res. 36, 1265-1272.

Lindesjöö, E., Thulin, J., Bengtsson, B.E., Tjaernlund, U., 1994 Abnomalities of a gill cover bonc, the operculum. in perch Perco fluvialitis from a pulp mill effluent area. Aquat. Toxicnl. 28, 189-207.

Loy, A., Mariani, I., Bertelletti, M., Tunesi, I.., 1998. Visualizing allometry: geometric morphometrics in the sturly of shape changes in the early stages of the 1wo-banded sea bream, Diplodus vilgaris (Percifomes, Sparidae). J. Morphol. 237, 137-146.

Loy, A., Boglione, C. Cataudella, S., 1999. Geometric morphometrics and morpho-anatumy: a combined tool in the study of sea bream (Sparzis aurata, Sparidae) shape. J. Appl. Ichthyol. I5, 104-110.

Loy, A., Boglione, C., Gagliardi, F.. Fenucci, L. Cataudella, S.. 2000 Geometric morphometrics and intemal anatomy in sea bass slape analysis (Dicentrarchus lahrax L., Moronidae). Aquaculture 186, $33-44$

Loy, A., Bertelletti, M. Costa, C., Ferlin, L., Cataudella, S., 2001 Shape changes and growth trajectories in the early stages of three species of the genus Diplodus (Perciformes, Sparidae). J. Morphol. 250. $24-33$.

Mourente, G. Rodrigne?, A.. Tocher, D.R.. Sargent, J.R., 1993. Effecls of dietary docosahevaenoic acid (DHA 22/6N-3) on lipid and fatty-acid cumpositions and growth in gilthead sea bream (Sparus aurata L.) larvae during first feeding. Acjuaculture 112, $79-98$

Papandroulakis, N., Divanach, P.. Kentouri, M. 2002. Enhanced biological performance of intensive sea bream (Sparus aurata) larviculture in the presence of phytoplankton with long photophase. Aquaculture 204, 45-63.

Paperna, 1., 1978. Swimbladder and skeletal deformations in hatchery bred Spanis anrata. J. Fish Biol. 12, 109-114.

Parra, G.. Yufera, M., 2000. Feeding. physiology and growth responses in first-feeding gilthead sca brean (Sparzs amrata L.) lanae in relation 10 prey density. J. Exp. Mar. Biol. Ecol. 243, 1 $\cdots 15$.

Polo, A., Yufera. M., Pascual, E., 199 1. Lffects of temperaturc on egg and larval development of Sparys auratn I. Aquaculture 92, 367-375.

Richtsmeier, J.T., DeLeon, V.B.. I.ele, S.R., 2002. The promise of geometric morphometrics. Yearb. Phys. Anthropol. 45,63-91.

Rohlt. F.J., 1993. Relafive warp analysis and an example of its application to mosquito wings. In: Marcus, L.F, Bello. E., GarcíaValdecasas, A. (Eds.), Contributions to Morphometrics. C.S.I.C., Madrid, pp. 131 159.

Rohlf. F. 1996. Morphometric spacc, shape components and the cffects of linear transformations. ln: Marcus. L.F., Corti, M., I.oy. A, Naylor, G.J.P., Slice, D.E. (Eds.). Advances in Morphometrics. Plenum Press, New York, pp. 117-129.

Rohlf, F. I, 2003. TpsSuluall: Thin Plate Spline Smal! Variation (Version 1.20). State University of New York at Stony Brook, Stony Brook, New York.

Rohl1, F J, 2004a. TpsUtil: Thin Plate Spline Utility (Version 1.33). State Iniversity of New York at Stony Bronk, Stony Brook, New York.

Rohlf, F.J., 2004b. TpsDig: 'Thin Plate S'pline Digitise (Version 1.40). State University of New York at Stony Brook. Stony Brock, New York.

Rohil, F.J., 2004c. TpsRegr: Thin Plate Spline Shape Regression (Version 1.29). Statc University of New York at Stony Brook, Stony Bronk, New York

Rohif, F.J., 2005. TpsRelw: Thin Plate Spline Relative Warp Analysis (Version 1.41). State University of New York at Stony Brook, Stony Brook. New York.

Rohlf, F.J., Slice, D.E., 1990. Extensions of the Procrustes method for the optimal superimposition of landmarks, Syst. Zool. 39, 40-59.

Rohlf. F.I.. Marcus, L.F., 1993. A revolution in morphometrics. Trends Ecal. [ivol, 8. 129-132.

Rohif. F.J., Loy. A., Corti. M. 1996, Morphometric analysis of nld world Talpidae (Mammalia. Insectivora) using partial-warn scores. Syst. Biol. 45, $344-362$.

Sadek, S., Osman, M.F. Mansour, M.A., 2004. Grok łl, surival and feed conversion rates of sea bream (Sparus ammata) cultured in earthen brackish water ponds fed different feed types. Aquacult. Tnt. 12, $409-421$

Tandler, A., Helps, S., 1985. The effects of photoperiod and water exchange-rate on growth and survival of gilthead sea brean (Sparus aurata. Linnaeus, Sparidae) from hatching 10 metamorphosis in mass rearing systerns. Aquaculture 48, 71-82.

Tare, D. Handwerker, T.S., 1994. Semi-operculum: A non-heritable bith defect in Tilapia nilotica. I. World Aquac. Soc. 25, 333-336.

Taylor, W.R., Van Dyke, G.C., 1985. Revised procedures for staining and clearing small fishes and other vertebrates for bone and cartilage study. Cybium 9, 107 119.

Valentin, A., Sérigny, J.M., Chanut, J.P., 2002. Geometric morphometrics reveals body shape differences between sympatric redfish Schastes mentalla, Sebastes fasciatus and their hybrids in the Gulf of St Lawrence. J. Fish Biol. 60, 857-875.

Van Snik. G.M.K.. Van den Boogaan, J.C.M. Osse, J.W.M.. 1997 Larval growth patterns in Cyprinus carpio and Clarias gariepinus with attention to the finfold. J. Fish Riol, 50, 1339-1352.

Winemiller, K.O., Taylor, D.H., 1982. Inhreeding depression in the convict cichlid, Cichlasoma nigrofasciatum (Baird and Girard). 1. Fish Biol. 21, 399-402. 
opercular deformities at $6.1 \mathrm{nmm}$ TL (Koumonindouros et al., 1997a) and 17 DPH (Galeotti et al.. 2000) in earlier studies, but these merhods are unpractical in daily quality assessment in commercial hatcheries. Konmoundourns et al. (1997a) proposed a metrical method to quantify and distinguish opercular deformitics during and after metamorphosis for quality assessment and experimentation on the causative factors. This method is based on the ratio of (1) the length from the posterior margin of the eye to the posterior margin of the operculum (pstOr) and the sum of (2) the eye diameter (ED) and (3) the length from the tip of the snout to the anterior margin of the eye (prOr) (thus ratio $=\mathrm{pstOr} /(\mathrm{prOr}+\mathrm{ED})$ ). Koumoundouros et al. (1995) also proposed several classic morphometric ratios (for example head length on TL) for the daily assessment of larval quality.

Our method, a discriminant function analysis performed on the shape variables obtained through landmark-based geometric morphometrics, could significantly separate deoperculated from normal specimens at $69 \mathrm{DPH}$, based on small shape differences of the extcrnal morphology, Our preliminary analysis, however; suggests that deoperculated specimens can be detected much earlier using geometric morphometrics (more specimens need to be analyzed, however. to support (his statistically). An automated geometric morphometric methor of the external morphology (e.g. hased on Fouricr analysis) could thus be a reliable, time and cost efficient method for quality assessment of reared fish stocks.

\section{Conclusion}

This preliminary study, using geometric morphometrics to detect and analyse opercular deformations in S. aurata, has yielded some new insights in the problem. First, the methodology proves to be very useful for understanding the nature of cranial deformations that occur in association with opercular deformations, as well as for screcning for shape changes related to it (both in the external and the skcletal morphology). Second, it has been shown that there cxists a striking left--right independency towards deoperculation. Third, even though a subtle size difference was observed at 65 DPH in normal and deoperculated specimens, allometries during growth appear to be very similar in normal and dcoperculated specimens.

Further sampling, however, is needed to test some of the observations, as well as to expand the size range in order to evaluate the earliest possible detection of opercular deformities in $S$. aurata, fiom which an easy detection protocol could be derived. Further testing of these observations with experimental setups will also be needed in order to understand causal factors behind deopcrculation.

\section{Acknowledgements}

We wish to express oul gratitude to general manager A. Moretti and the co-workers at the $S$. aurata hatchery Maricoltura di Rosignano Solvay and the associates at INVE technologies for the kind supply of specimens and arranging of the mectings. We also wish to thank our lab technician M. Brunain for the clearing and staining of the specimens which were used for the osteological analysis.

\section{References}

Adams, M.S. Niswander, I.D.. 1967. Developmental 'noise' and congenital malformation. Gen. Res. Comp. 10. 313 -317.

Adams, D.C., Rohlf, F.J., Slice, D.E. 2004. Geometric morphometrics: ten years of progress following the 'revolution'. Ital. J. Zool. 71, 5-16.

Alfonso. J.M.. Montero, I)., Robaina, L., Astorga, N., Izquierdo, M.S., Gimes, R., 2000. Association of lordosis -scoliusis - kyphosis deformity in gilthead sea brcam (Sponis caurata) with family structure. Fish Physiol. Biochem. 22, 159-I63.

Andrades. J.A., Вecerra, 1.. Femández-Llebrez. P., 1996. Skeleta] deformities in larval, juvenilc and adult stages of cultured gilthead sea brcam (Spanzs amata I..). Aquaculture 141, 1-11.

Amquist, G., Mårtensson, T., 1998. Measurement error in geometric morphometrics: empirical stratcgies to assess and reduce its impact on measures of shape. Acta Zuol. Hung. 44, $73-96$.

Balon, E.K., 1975. Terninology of intervals in fish development. J. Fish. Res. Board Can. 32, 1663-1670.

Barahoma-Femandes, M.HL. 1982. Bocty deformation in hatchery reared Eurnpean sea bass Dicentrarchus labrax (L.). Types, prevalence and effect on fish survival. I. Fish Biol. 21, 239-249.

Beraldo. P., Pinosa, M., Tibaldi, E.. Canavese, B.. 2003. Abnormalities of the operculum in gilthead sea bream (Spants aurata): morphological description. Aquaculture 220, 89-99.

Boglione, C., Cagliardi, F. Scardi, M., Cataudella, S.. 2001. Skeletal descriptors and quality assessment in larvae and post-larvae of wildcanght and hatchery-reared gilthead sea brean (Sparus aurara L. 1758). Aquaculture 192, 1-22.

Bookstein, F.L., 1990. Int1oduction to methods for landmark data, In: Rohlf, F.J., Bookstein, F.L. (Eds.), Proceedings of the Michigan Morphometrics Workshop, pp. 215-225.

Cahu, C., Infante, J.Z.. Takeuchi, T., 2003. Nutritional components affecting skeletal development in fish lan ae. Aquaculture 227, 245-258.

Cavalcanti, M.J., Montciro. L.R., Lopes, PR.D. 1999. Landmarkbased morphometric analysis in selected species of serranid fishes (Perciformes: Teleostei). Zool. Stud. 38, 287-294.

Chatain. B., 1994. Estimalion et ancélioration des performances zootechniques de l'élevage larvaire de Dicentrarchus labrax et de Sparus aurata. Thèse Doctorale en Sciences, Université d'AlxMarseille IL $199 \mathrm{pp}$.

Chatain, B.. Ounais-Guschemann, N., 1990. Inproved rate of initial swimbladder inflation in intensively reared Sparus aurata. Aquaculture 84. 345-35.

De Wolf, T., Courtens, V., Capiferri, U., Pirone, A., Lenzi, C. Lenzi, F, 2004. The influence of light cunditions on the operculum recovery of sea bicam (Sparus aurata L.) fry: Book of abstracls. Aquaculture Europe 2004, Biotechnologies for quality, Barceiona. Spain 20-23 October, 2004, p. 292.

Dodson, P., 1978. On the use of ratios in growtl studies. Syst. Zool. 27. $62-67$ 